\title{
Fighting the Bullying Epidemic: A Practitioner Inquiry into the Effects of an Intervention Strategy on Reaction to Bullying in School-Aged Children with Speech Disabilities
}

\author{
Sohel Bagai', Carolyn Erratt ${ }^{2}$ \\ ${ }^{1}$ Junior at El Modena High School, Orange, CA, USA \\ ${ }^{2} \mathrm{McPherson}$ Magnet School, Orange, CA, USA \\ Email: sohelbagai@icloud.com
}

How to cite this paper: Bagai, S., \& Erratt, C. (2019). Fighting the Bullying Epidemic: A Practitioner Inquiry into the Effects of an Intervention Strategy on Reaction to Bullying in School-Aged Children with Speech Disabilities. Creative Education, 10, 26-35. https://doi.org/10.4236/ce.2019.101002

Received: December 9, 2018

Accepted: January 7, 2019

Published: January 10, 2019

Copyright ( 2019 by author(s) and Scientific Research Publishing Inc. This work is licensed under the Creative Commons Attribution International License (CC BY 4.0).

http://creativecommons.org/licenses/by/4.0/

\begin{abstract}
Students with speech disabilities frequently experience bullying and associated stress and anxiety in school. There is a need for these students to improve coping skills and reduce stress and anxiety when interacting with other students and adults. The purpose of this experiment was to create a program based on the technique of self-empowerment and role-modeling that would reduce these symptoms. We explored whether exposing these children to role models would increase their coping ability. This program was designed by a student with a speech disability in coordination with a clinical speech pathologist.
\end{abstract}

\section{Keywords}

Fighting, Bullying Epidemic

\section{Introduction}

Our desire is to engage in this collaborative inquiry originated in the 2017-2018 academic year when a high school student with a speech disability, who is also first author of this research experienced bullying from peers without disabilities. This student noted that other students with speech disabilities, like himself, did not have the coping skills to deal with bullying. This observation prompted the student to collaborate with his speech pathologist to develop a program of coping skills for elementary and middle school students with speech disabilities.

Bullying is defined as a repeated exposure to unsolicited negative actions by 
one or more students over time (Olweus, 1994). Studies report that $30 \%$ of all children and $84 \%$ of children with disabilities will experience some form of bullying (Batsche \& Knoff, 1994). Children who are victims tend to be rejected by peers, have fewer friends, and are less accepted by their peers than children who are not bullied (Card \& Hodges, 2008). Additionally, students who have been bullied frequently show signs of anxiety and depression, poor grades, low self-esteem, or even suicide (Berthold \& Hoover, 2000). Speech-disabled children are especially vulnerable to bullying because of their inability to voice their opinion. However, teachers and administrators have few tools to combat physical and verbal aggression and social rejection that students with disabilities face while still adhering to the common core standards. Budget and time constraints further prevent educators from open dialogues with non-disabled students on how to interact with students with disabilities. Thus, there is a critical need for an intervention that can be easily implemented in classrooms and would reduce victimization of speech-disabled students.

An interactive and open discussion about bullying behaviors between teachers and victims in a safe environment can foster self-confidence and self-empowerment (Cummings et al., 2006). The purpose of our project was to provide speech therapists, teachers, and speech-disabled students with a tool that would facilitate communication about bullying. To fulfill this objective, we asked an overarching question: Can students with disabilities better cope with bullying if they can identify strengths within themselves? Could this increase their self-confidence and help them feel less intimidated?

We describe a self-assessment questionnaire-based project which throws light on the deep-rooted fears of bullying victims. The goal of this project is to provide an insight into our district wide effort to create a safer environment for the speech-disabled children and to give them a "voice" to help themselves.

\section{Theoretical Framework}

This project evaluates the firsthand experiences of the speech-disabled author with bullying and his journey to overcome it by empowering other students. The key components of this project were: 1) the autobiographical study and critical self-awareness of the pervasive injustice of bullying the "weak", 2) empowering the weak to not let their disability or bullying define their existence, and 3) the role that school speech therapists can play as they work with students facing these challenges.

While individual variables play a prominent role in bullying and victimization, peer groups are a major socialization force during early adolescence. The period of transition from elementary school to middle school is a potential stressor associated with a temporary increase in bullying during early adolescence (NCES, 1995; Pellegrini, 2002). Perry et al. (2001) found that children with feelings of low self-worth, helplessness, and incompetence are especially targeted by bullies. Increasing children's knowledge about how they might respond to 
bullying is consistent with positive improvements in bullying prevention (Merrell et al., 2008). Such discussion between teachers and victims in a safe environment can foster self-confidence and self-empowerment (Cummings et al., 2006). We used these insights to develop and implement a collaborative effort between teachers and students to combat bullying.

We first developed a self-assessment questionnaire that allowed teachers to initiate a dialogue about bullying with speech-disabled students. In the ensuing dialogue, teachers helped speech-disabled children identify their own strengths and gain confidence in themselves. We used role model-based storytelling and reflection sessions to help students identify and focus on their strengths and not their disability. We then used a process of writing or drawing for students to deepen recognition of their own attributes. This process of self-reflection allowed students to gain confidence and identify ways of combating bullying. As teachers read the students' responses on the questionnaires and reviewed their writing and/or drawings, they too gained insight into the challenges that their speech-disabled students faced.

\section{Methodology}

In 2017-2018, the first author published his own experiences of being bullied in an autographical children's book, "The Stuttering Little Ballet Boy" (Bagai, 2015). As the student shared his book with elementary and middle school teachers, they expressed an interest in using the book as a motivational tool in the classroom. This led to a series of meetings in which the author met with speech and language pathologists of the school district. A team to explore the extent to which children with speech disabilities were experiencing bullying in their classrooms was formed.

Ninety-two students with speech disabilities and ten speech therapists in a local school district elected to participate in this study. These students were selected from the group of student undergoing speech therapy at the elementary schools of the Orange Unified School district. The students participated in the study as part of the class activity. First, students with speech disabilities read a motivational book that was written by the first author himself a student who suffers from stuttering. Then the speech therapists administered a stress and coping skills questionnaire and documented classroom discussions after the students had read the book. Finally, we qualitatively analyzed the responses and collaborated systematically to develop and implement pedagogies to empower our children and create an environment of mutual respect.

\subsection{Questionnaire Development}

As a first step, we searched for a bullying scale that elementary and middle school children could read and understand independently with little or no help. Several instruments of bullying experiences have been described by the National Center for Injury Prevention and Control of the Centers for Disease Control and 
Prevention. Please see "Measuring Bullying Victimization, Perpetration, and Bystander Experiences: A Compendium of Assessment Tools" for varying instruments of bullying experiences (https://www.cdc.gov/violenceprevention/pdf/bullycompendium-a.pdf). A review of these scales revealed that most focused on physical or verbal aggression, harassment, and social isolation. In our discussions with young students with speech disabilities and their caregivers, we found that none of the existing scales adequately captured their experiences. Specifically, the children reported that they were not subject to physical or verbal aggression. Instead, they reported that students without disabilities "looked at them weirdly" or told them that they "talked weird". Additionally, most elementary and middle school students were unable to comprehend the existing questionnaires even when the questions were read aloud to them.

We therefore created a simplified questionnaire that children with speech disabilities between the ages of 7 through 12 years could relate to and which would allow them to self-report their experiences without feeling threatened. Our survey was adapted from existing questionnaires with input from students affected by speech disabilities, a speech pathologist, language pathologists, and classroom teachers. An initial version of the questionnaire was piloted among 10 students before a final version was developed (Appendix 1). The final questionnaire consisted of five items: one item on frequency of bullying, one item on whether the student had ever reported bullying, two items on coping strategies (school avoidance, hiding in the bathroom), and one item on the effect of bullying on the students responses were reported on a 4-point Likert scale ranging from "never", "sometimes", "often", to "very often".

\subsection{Implementation of the Intervention}

The intervention was implemented in forty-minute regularly-scheduled speech therapy group sessions held in a classroom setting. Ninety-two primary and middle school students in 9 schools (approximately 2 to 10 students per session) participated. The speech therapist first explained the purpose of the project to the students. After the students had completed the questionnaire, the speech therapist read aloud the book, "The Stuttering Little Boy". This illustrated children's book describes the journey of a male middle school student who suffers from stuttering and overcomes his disability by learning Ballet. Next, the teacher moderated a discussion in which the students were asked about their own strengths. Finally, the students recorded their reflections through drawing and/or writing. We also obtained speech and language pathologists' generated sources that included their observational notes from the classroom discussion as well as their reflections. Members of the community, who participated in our meetings, also contributed in the form of relevant reflections.

\subsection{Data Analysis}

Responses were analyzed using N'Vivo software version 11 (QSR International, 
Doncaster, Victoria, Australia). Principles of qualitative thematic analysis were used to synthesize and summarize findings from the individual reflections or drawings. A set of two individuals involved with the research study independently coded each reflection. Following coding of the transcripts, key phrases were naturally grouped together to form preliminary themes, from which emergent concepts arose. Illustrative quotations were used to support the themes and concepts.

\section{Results}

Analysis of questionnaire data from 92 students revealed that $82 \%$ reported had experienced bullying at least "sometimes". Of these, $87 \%$ had "never" reported the episode to an adult. More than $60 \%$ students $(n=55)$ reported that they avoided going to school or hid in the bathroom to cope with bullying. All students $(100 \%)$ reported that they felt "nervous or shy" when talking to other students or adults.

In the motivational story that was read in the classroom, a speech disabled boy persuades his mother to allow him to join a ballet class. The book describes the boy's journey as he finds fulfillment and confidence through dance. Ultimately, he gets an opportunity to perform on stage, an event that is watched by many of his peers. As the "ballet boy" gains in confidence, he is empowered to stand up to bullying in the classroom.

Several themes emerged from analysis of student drawings, narratives, and teacher reflections. At the beginning of the session, many students were fearful and reticent about discussing their bullying experiences. After completing the survey, the students were more willing to talk about their experiences. Few students reported suffering verbal or physical aggression. Most described episodes where a student without a disability had called them "weird" or "looked at me weirdly". Most simply stated that they felt "different" from their peers. Several students described feelings of guilt and shame that they had done something wrong to make their peers behave negatively towards them. They also felt excluded from play and conversations in the classroom or during recess. Most students had not reported the incidents to an adult due to shame; some feared rebuke from adults that "they should try to talk better".

After the motivational story was read aloud, students began by identifying with the speech-disabled boy in the story. They became animated when the class discussed the part of the story where the boy discovers ballet. Students described activities that made them happy e.g. music, sports, taking care of pets, baking, solving math problems, video games, photography, doing yoga, or fixing a car or a computer with a parent. The teachers observed that as the discussion deepened, students began to focus on their strengths, instead of feeling "different" or ashamed about their disability. Many drew pictures or wrote narratives describing their accomplishments (Figures 1-4). One student stated, "I can be famous like the ballet dancer too". Other students also expressed pride in their 
accomplishments. The student who played soccer talked about winning the world cup, another student envisioned sending rockets to space, a third student wanted to start scouting locations for her future bakery. Towards the end of the class, students described greater confidence in how they would cope with bullying. One student noted, "I did not realize I could do something about being bullied". Another student stated, "I don't care if they laugh at me. I am smarter than they are!" Analysis of parent reflections showed that students came home energized and excited and more willing to participate in social and family activities than in the past.

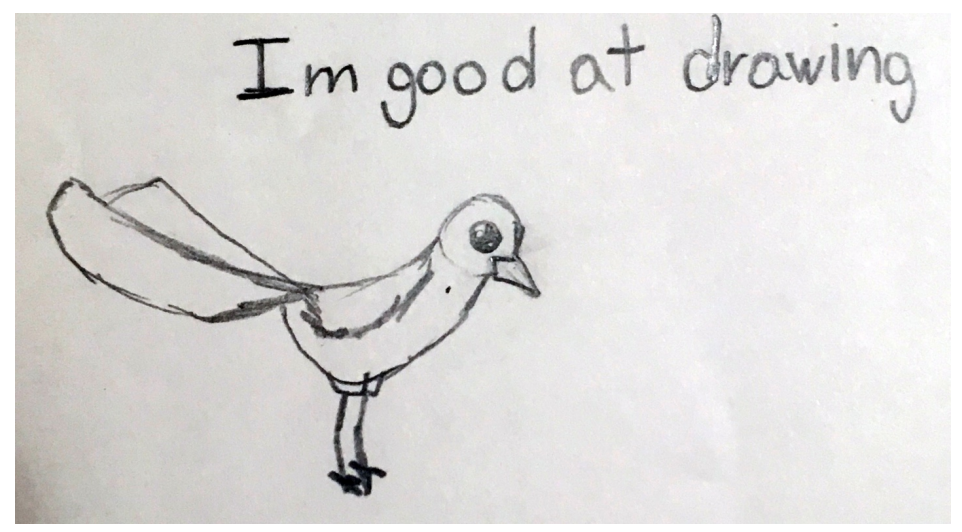

Figure 1. This student was inspired by the project to take pride in his artistic abilities.

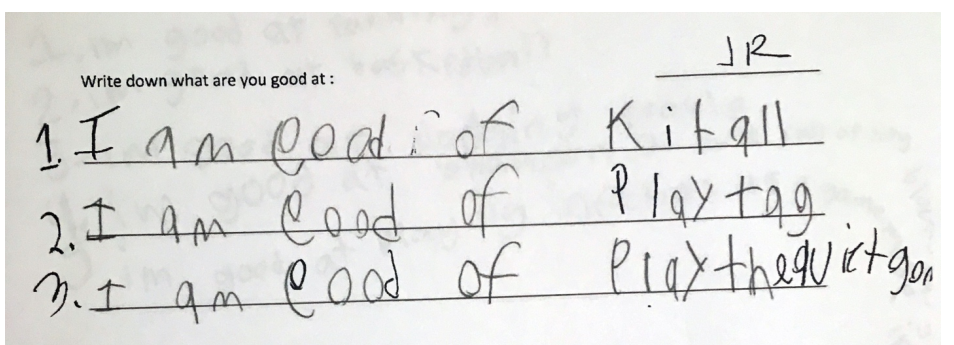

Figure 2. I am good at kickball, playing tag, and playing the quiet game.

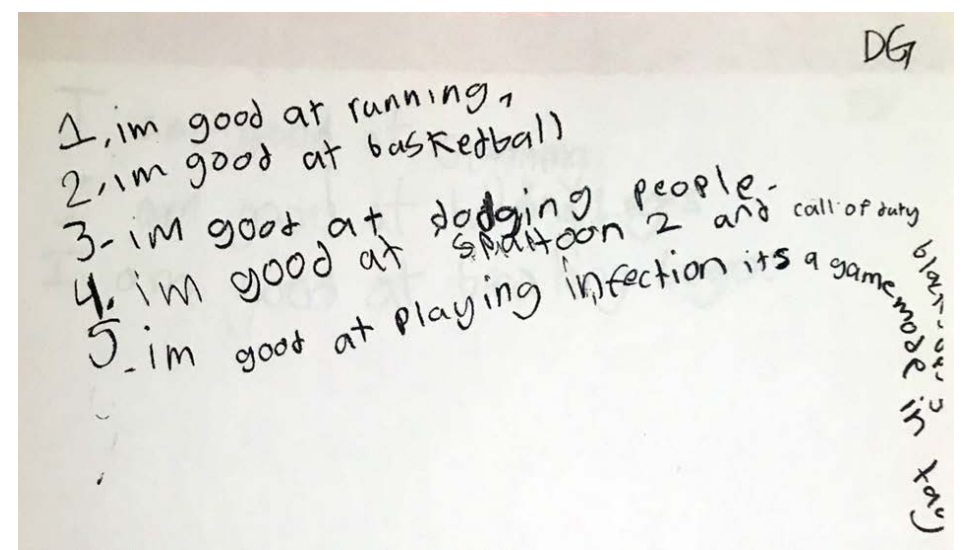

Figure 3. I am good at running, basketball, dodging people, Splatoon 2, Call of Duty, Black Ops 3, and infection which is a game mode in tag. 


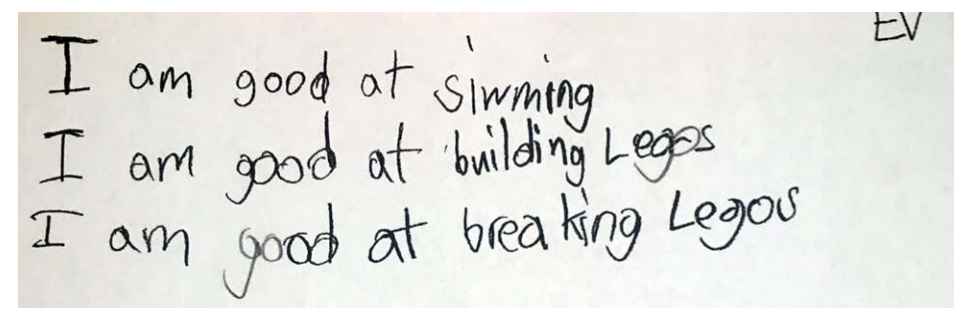

Figure 4. I am good at swimming, building Legos, and breaking Legos.

\section{Discussion}

Our project created space in speech and language therapy classrooms where elementary and middle school students with speech disabilities could explore their subjective experiences with bullying and the impact that it has on their lives. We show how a simple questionnaire opens a dialogue on a topic that greatly affects the life of speech-disabled students but is rarely discussed in the classroom. We demonstrate how by reading aloud a motivational book about a positive role model, teachers, and therapists can empower speech-disabled students to identify their own strengths. When speech-disabled children were encouraged to identify positive traits in themselves, they gained in confidence and felt excited about their future. Within the space of a single session, they gained the insight that they were not defined by their disability and that by focusing on their strengths, they could cope with bullying.

Bullying is a direct consequence of a real and perceived imbalance of power. We realize that no single initiative can resolve the rapidly growing brutality of bullying in schools and on social media. Our project is rooted in the underlying theoretical framework of social justice and how raising critical self-awareness in speech-disabled students can empower them to gain in self-confidence and improve their coping skills. Our project also raises awareness about bullying among teachers and professionals who work with speech-disabled students and provides them with a simple means of helping their students combat this pervasive problem.

Our study has several strengths. Our coping questionnaire was created from the unique perspective of elementary and middle school students with speech disabilities and served as a "tool" that allowed teachers to initiate dialogue about bullying. We also conducted our intervention in the safe-zone of the speech therapy classroom where most other students had undergone similar experiences and no student felt singled-out. The non-threatening environment led to an open discussion about bullying behaviors and allowed students to discuss their experiences without fear of retribution. Finally, our study engaged teachers and professionals who work with speech-disabled students and who provided insight into how these students could be empowered to learn skills to combat bullying.

Our study also has several limitations. Our intervention was conducted at a single-time point in speech therapy classrooms. Longer term studies with follow up are required to determine if interventions such as ours result in lasting im- 
provement in coping skills and fewer episodes of bullying of disabled students. Studies with larger sample size across several school districts would also allow us to determine the generalizability of our findings and if similar programs can be developed for students with other kinds of disabilities. Our study also does not incorporate the perspective of students who participate in bullying, many of who may be suffering from significant social and emotional problems of their own (Pellegrini, 2002).

Traditionally, anti-bullying programs have focused on greater acceptance of vulnerable peers and a decrease in approval of bullying groups (Langevin \& Prasad, 2012). Our study shows that a fundamental empowerment of victims occurs when they proactively participate in anti-bullying programs. We recommend that antibullying programs involve the victims along with the anti-bullying activists. Proactive participation of disabled students will empower bullying victims to educate their able-bodied peers in why they are different, how they feel when they are being teased or bullied and create a united effort that could break the endless cycle of bullying.

\section{Conclusion}

Students with disabilities lack the skills to deflect the overt aggression of bullying and integrate with their peers. In the process of collectively and individually filling out the questionnaires and participating in a workshop in the safety of their classrooms, speech-disabled children in our school worked through the delicate but brutal reality of their everyday struggles with bullying. Our collaborative effort mobilizes multiple perspectives including that of the victims, speech and language pathologists, and community activists to allow an open dialogue and empower the community as a whole to combat bullying.

In a world where majority of the children with speech disabilities will experience some form of bullying, our inquiry aims to put power in the hands of the victims to take charge of their wellness. Our project gives adults and children an opportunity to explore their new-found awareness of what the most vulnerable victims go through and the importance of creating a safe channel to voice their opinion without the fear of victimization. Our work is of significance to educators, speech and language pathologists, administrators, parents, and curriculum developers who are interested in creating an equal platform in which no child is bullied.

\section{Acknowledgements}

Authors acknowledge the support and encouragements of speech pathologists of Orange Unified School district.

\section{Conflicts of Interest}

The authors declare no conflicts of interest regarding the publication of this paper. 


\section{References}

Bagai, S. (2015). The Stuttering Little Ballet Boy. https://www.amazon.com/Stuttering-Little-Ballet-Sohel-Bagai-ebook/dp/B01MUELJ0 W

Batsche, G. M., \& Knoff, H. M. (1994). Bullies and Their Victims: Understanding a Pervasive Problem in the Schools. Psychology Review, 23, 165-174.

Berthold, K. A., \& Hoover, J. (2000). Correlates of Bullying and Victimization among Intermediate Students in the Midwestern USA. School Psychology International, 21, 65-78. https://doi.org/10.1177/0143034300211005

Card, N. A., \& Hodges, E. (2008). Peer Victimization among Schoolchildren: Correlations, Causes, Consequences, and Considerations in Assessment and Intervention. School Psychology Quarterly, 23, 451-461. https://doi.org/10.1037/a0012769

Cummings, J., Pepler, D., Mishna, F., \& Craig, W. (2006). Bullying and Victimization among Students with Exceptionalities. Exceptionality Education Canada, 16.

Langevin, M., \& Prasad, N. (2012). A Stuttering Education and Bullying Awareness and Prevention Resource: A Feasibility Study. Language, Speech, and Hearing Services in Schools, 43, 344-358. https://doi.org/10.1044/0161-1461(2012/11-0031)

Merrell, K. W., Gueldner, B., Ross, S., \& M. Isava, D. (2008). How Effective Are School Bullying Intervention Programs? A Meta-Analysis of Intervention Research. School Psychology Quarterly, 23, 26-42. https://doi.org/10.1037/1045-3830.23.1.26

NCES (National Center for Educational Statistics) (1995). Strategies to Avoid Harm at School. Washington DC: U.S. Department of Education, Office of Educational Research and Improvement.

Olweus, D. (1994). Bullying at School: Basic Facts and Effects of a School Based Intervention Program. Journal of Child Psychology and Psychiatry, and Allied Disciplines, 35, 1171-1190. https://doi.org/10.1111/j.1469-7610.1994.tb01229.x

Pellegrini, A. D. (2002). Bullying, Victimization, and Sexual Harassment during the Transition to Middle School. Educational Psychologist, 37, 151-163. https://doi.org/10.1207/S15326985EP3703_2

Perry, D. G., Hodges, E. V. E., \& Egan, S. K. (2001). Determinants of Chronic Victimization by Peers. In J. Juvonen, \& S. Graham (Eds.), Peer Harassment in Schools: The Plight of the Vulnerable and Victimized (pp. 73-104). New York: Guilford Press. 


\section{Appendix 1}

\section{STRESS AND COPING SKILLS}

Date: Grade: Age: Gender: M F

$1=$ Never $\quad 2$ = Sometimes $\quad 3$ = Often $\quad 4=$ Very Often

Please circle what you feel.

1) Have you been teased or bullied? 1234

2) If you are teased or bullied do you report it to anyone? 1234

3) Do you avoid going to school because of teasing? 1234

4) Do you cry or go to the bathroom when you are teased? 1234

5) Do you feel nervous or shy when you talk to the other kids 1234 or grown-ups?

Intervention:

1) Read the book.

2) Identify what you are good at.

3) Write it down.

4) Do the questionnaire again. 